\title{
Adverse respiratory effects associated with cadmium exposure in small-scale jewellery workshops in India
}

\author{
Subhabrata Moitra, ${ }^{1}$ Paul D Blanc, ${ }^{2}$ Subhashis Sahu ${ }^{1}$
}

${ }^{1}$ Ergonomics and Occupational Physiology Laboratory, Department of Physiology, University of Kalyani, Kalyani, West Bengal, India

${ }^{2}$ Division of Occupational and Environmental Medicine, University of California San Francisco, San Francisco, California, USA

\section{Correspondence to}

Dr Subhashis Sahu,

Ergonomics and Occupational

Physiology Laboratory,

Department of Physiology,

University of Kalyani,

Kalyani-741235, West Bengal, India;

skcsahu@yahoo.co.in

Received 23 November 2012 Revised 8 February 2013

Accepted 14 February 2013

Published Online First

6 March 2013

\section{ABSTRACT \\ Background Cadmium (Cd) is an important metal with both common occupational and environmental sources of exposure. Although it is likely to cause adverse respiratory effects, relevant human data are relatively sparse.}

Methods A cross-sectional study of 133 workers in jewellery workshops using $\mathrm{Cd}$ under poor hygienic conditions and 54 referent jewellery sales staffs was performed. We assessed symptoms, performed spirometry, measured urinary $\mathrm{Cd}$ levels in all study subjects and quantified airborne total oxidant contents for 35 job areas in which the studied workforce was employed. We tested the association of symptoms with exposure relative to the unexposed referents using logistic regression analysis, and tested the association between urinary $\mathrm{Cd}$ levels and lung function using multiple regression analysis, adjusting for demographics, smoking and area-level airborne oxidants.

Results Exposed workers had 10 times higher urinary $\mathrm{Cd}$ values than referents (geometric mean 5.8 vs $0.41 \mu \mathrm{g} / \mathrm{dl} ; \mathrm{p}<0.01$ ). Of the exposed subjects, $75 \%$ reported respiratory tract symptoms compared with $33 \%$ of the referents $(\mathrm{OR}=3.1,95 \% \mathrm{Cl} 1.4$ to 7.3$)$. Forced vital capacity (FVC) and forced expiratory volume in $1 \mathrm{~s}$ $\left(\mathrm{FEV}_{1}\right)$ were also lower among the exposed workers than the referents ( $>600 \mathrm{ml}$ decrement for each, $p<0.001)$. For every $1 \mu \mathrm{g}$ increase in urinary $\mathrm{Cd}$ there was a $34 \mathrm{ml}$ decrement in FVC and a $39 \mathrm{ml}$ decrement in $\mathrm{FEV}_{1}$ $(p<0.01)$, taking into account other covariates including workplace airborne oxidant concentrations.

Conclusions This cohort of heavily exposed jewellery workers experienced frequent respiratory symptoms and manifested a marked deficit in lung function, demonstrating a strong response to $\mathrm{Cd}$ exposure.

\section{INTRODUCTION}

The process of making gold-containing ornamental metal jewellery and related objects comprises three stages: alloying metal for its intended use; fabricating the intended object, which can include soldering or brazing; and polishing or buffing the completed piece. Each of these stages of the production process can lead to various metallic (eg, cadmium (Cd)) and non-metallic (eg, fume) exposures of potential health concern.

$\mathrm{Cd}$ metal is one such exposure. $\mathrm{Cd}$ is a component of certain metal solders, including so-called 'gold carat' solders used in jewellery fabrication. In addition, $\mathrm{Cd}$ can be employed as a metal additive in jewellery alloying, combined with gold and silver to produce what is sometimes called 'green gold'. Cd is a well-established respiratory toxin. ${ }^{1}$ Acute high-level

\section{Key messages}

What is the key question?

- Is occupational cadmium exposure associated with pulmonary function impairment?

What is the bottom line?

- The poor hygienic conditions in Indian jewellery making workshops that entail cadmium overexposure linked to clinically relevant lung function deficits.

\section{Why read on?}

- Past data on this topic have been mixed; this study provides convincing support for the adverse target organ effects of chronic cadmium inhalation.

human inhalation exposure, typically through flame cutting or brazing Cd-containing materials, is associated with acute lung injury and diffuse alveolar damage. ${ }^{2}$ In experimental animal models, repeated $\mathrm{Cd}$ inhalation causes emphysema. ${ }^{45}$ There is also evidence that human exposure can have a similar adverse effect. Indeed, the natural $\mathrm{Cd}$ content of cigarettes or environmental $\mathrm{Cd}$ exposure interactions with cigarette smoking may be mechanisms underlying obstructive lung disease caused by smoking. ${ }^{67}$

Thus, delineating the respiratory effects of subacute and chronic inhalation of $\mathrm{Cd}$ is of both occupational and wider public health importance. To date, the seminal report of Davison and colleagues has best described a heavily Cd-exposed cohort, ${ }^{8}$ although there have been other limited investigations of this topic, some of which have shown an adverse respiratory effect ${ }^{9-12}$ while other studies have not. ${ }^{13-15}$ We report our findings among a group of $\mathrm{Cd}$-exposed jewellery workers in whom Cd levels and lung function data were systematically analysed.

\section{METHODS}

Overall study design and subject participation

We performed a cross-sectional study among workers engaged in manufacturing gold jewellery that involved the use of Cd-containing solder, including persons with varying duties and a range of anticipated exposure levels. A total of 233 men were screened from 276 potential study participants randomly identified among a total workforce estimated to be 350 in 35 working areas. Women are not employed in this industry in the region studied. The 
Table 1 Baseline characteristics of the participants

\begin{tabular}{llll}
\hline Characteristic & Referent $(\mathbf{n}=\mathbf{5 4})$ & Exposed $(\mathbf{n}=133)$ & $\mathbf{p}$ Value \\
\hline Age (years) & $37.6(5.6)$ & $35.7(4.7)$ & 0.39 \\
Body mass index $\left(\mathrm{kg} / \mathrm{m}^{2}\right)$ & $23.4(3.2)$ & $22.5(2.8)$ & 0.54 \\
Height $(\mathrm{m})$ & $1.71(0.14)$ & $1.68(0.12)$ & 0.62 \\
Ever smoker & $14(25.9 \%)$ & $43(32.3 \%)$ & 0.49 \\
Regular exposure to SHS & $16(29.6 \%)$ & $49(36.8 \%)$ & 0.44 \\
Parental asthma & $3(5.5 \%)$ & $7(5.3 \%)$ & 0.94 \\
\hline $\begin{array}{l}\text { Data are presented as mean (SD) or } \mathrm{n}(\%) . \\
\text { SHS, second-hand smoke. }\end{array}$
\end{tabular}

workshops were located within a $200 \mathrm{~km}$ radius of Kolkata, West Bengal. The study was carried out between late February and early April 2012.

Of the 276 workers screened for participation, we excluded subjects for the following reasons: current antibiotic therapy; being under the supervision of a healthcare provider for an active medical condition; or failing to perform spirometry successfully. After excluding 22 potential jewellery sales staffs and 67 exposed workers, 187 (80\% of the recruited group) remained. The mean age was similar in the excluded participants and the included group $(35.7 \pm 5.9$ years vs 36.2 \pm 5.0 years; $\mathrm{p}=0.38$ ). There were proportionally fewer ever smokers among the excluded group than among those included $(16.9 \%$ vs $30.5 \% ; \mathrm{p}<0.05)$. Of the 187 participants included in the final analysis, $133(71 \%)$ worked in active production and $54(29 \%)$ were personnel associated with sales of the jewellery products that had been manufactured (the referent category in this analysis). The exposed group was further subcategorised by job type: metal melting/alloying $(n=32)$; design and fabrication including flame cutting metal pieces and soldering/brazing $(n=61)$; and jewellery buffing and polishing $(n=40)$. Metal melting was generally carried out with charcoal burning in ceramic vessels. Flame cutting and brazing employed liquefied petroleum gas and a manual blow pipe. Buffing and polishing used predominantly manual tools with acid solutions for cleaning. The workers did not move among these three subcategories of employment.

\section{Questionnaire assessment}

We administered a structured questionnaire containing items on respiratory health, occupational exposure and lifestyle factors. This questionnaire was modified from the European Community Respiratory Health Survey ${ }^{16}$ and translated into Bengali. An English back-translation was used for validation.
Subjective respiratory complaints in the previous 12 months by questionnaire were categorised by symptom group. These included: (1) acute/current or chronic/prolonged cough; (2) acute or chronic wheezing or whistling of the chest; (3) production of phlegm; (4) breathing trouble; (5) nasal problems (irritation in nose, dryness or stuffy nose, sneezing, runny or blocked nose); (6) eye problems; (7) nasal problems with watery eyes; and (8) skin symptoms such as dryness, rashes, patchiness, irritation, dark spots, burns or swelling.

\section{Lung function}

We measured lung function using a computerised spirometer (Maestros Mediline Systems Ltd., India), consistent with American Thoracic Society guidelines, ${ }^{17}$ using the best of three values for forced vital capacity (FVC) and forced expiratory volume in $1 \mathrm{~s}\left(\mathrm{FEV}_{1}\right)$. Predicted values used Indian population values. ${ }^{18}$ Spirometry was performed at sites removed from the workshops studied to avoid concomitant acute irritant exposures.

\section{Measurement of urinary cadmium level}

The first morning urine sample was collected by subjects in a standard glass container (Borosil, India) at home before coming to work. The concentration of $\mathrm{Cd}$ in the urine samples was quantified using atomic absorption spectroscopy (PerkinElmer, USA). Urine creatinine was not measured.

\section{Measurement of total airborne oxidants in the workplace}

We measured area-level total airborne oxidants (TAO) using a portable air monitor sampling pump employing impinger collection and a phenolphthalein-based colorimetric assay (LaMotte, USA), consistent with methods initially developed by Haagen-Smit and Brunelle to assess ambient air pollution. ${ }^{19}$ Concentrations are quantified in parts per million (ppm) total oxidant content. Air quality was monitored in the workshops as well as in the shops. Different workstations of the three different subcategories of tasks (melting, fabrication and polishing) were sampled. When more than one subcategory existed at a single employment site, the areas were not open to each other although some cross-contamination was possible. Sampling for referents was performed in their work offices. A minimum of four recordings of $10 \mathrm{~min}$ sampling duration at 1 litre flow rate was made at each work site studied and the mean value was calculated. The area-level measurement was assigned as the exposure level for all of the workers in that area. Measurements were made for the work areas of all the participants included in the analysis.

Table 2 Comparison of urinary cadmium levels between referents and exposed workers and among the exposure subcategories

\begin{tabular}{|c|c|c|c|c|}
\hline $\begin{array}{l}\text { Exposure group } \\
\text { comparisons }\end{array}$ & $\begin{array}{l}\text { Geometric } \\
\text { mean } \pm S D\end{array}$ & Median & $\begin{array}{l}\text { 25th-75th } \\
\text { percentile }\end{array}$ & Range \\
\hline \multicolumn{5}{|l|}{ Referent vs exposed workers } \\
\hline Referent $(n=54)$ & $0.41 \pm 0.11$ & 0.43 & $0.29-0.54$ & $0.18-0.78$ \\
\hline Total exposed $(n=133)$ & $5.80 \pm 0.38$ & 5.91 & $4.17-8.18$ & $2.74-9.89$ \\
\hline \multicolumn{5}{|l|}{ Across exposure subcategories } \\
\hline Melting/alloying $(n=32)$ & $4.85 \pm 0.19$ & 4.93 & $4.16-5.76$ & $3.17-7.33$ \\
\hline Fabricating $(n=61)$ & $8.31 \pm 0.10$ & 8.32 & $7.83-8.99$ & $6.22-9.89$ \\
\hline Buffing/polishing ( $n=40$ ) & $3.87 \pm 0.15$ & 3.91 & $3.52-4.37$ & $2.74-5.90$ \\
\hline
\end{tabular}


Table 3 Area-level total airborne oxidants by exposure category

\begin{tabular}{|c|c|c|}
\hline Exposure category (sample $n$ ) & Median & Range \\
\hline \multicolumn{3}{|l|}{ Referent vs exposed workers } \\
\hline Referent workplaces $(n=13)$ & 85.3 & $68.1-92.4$ \\
\hline Total exposed workplaces $(n=22)$ & 270.3 & $138.3-510.0$ \\
\hline \multicolumn{3}{|l|}{ Across exposure subcategories } \\
\hline Melting/alloying areas $(n=10)$ & 271.3 & $210.7-310.7$ \\
\hline Fabricating areas $(n=7)$ & 150.0 & $138.3-175.3$ \\
\hline Buffing/polishing areas $(n=5)$ & 450.0 & $420.0-510.0$ \\
\hline
\end{tabular}

\section{Data analysis}

To graphically display urine $\mathrm{Cd}$ values, they were transformed into the natural logarithm of 1 plus the observed value (to avoid negative values for concentrations $<1.0 \mu \mathrm{g} / \mathrm{dl}$ ). To test differences between the exposed and referent groups we used the $\chi^{2}$ or unpaired $t$ test. Differences in spirometric data among groups were tested using one-way analysis of variance. To test differences between urinary $\mathrm{Cd}$ (expressed as the geometric mean) among the referents compared with all the exposed workers as a group, we used the Mann-Whitney U test. To test differences in pairwise comparisons of urinary $\mathrm{Cd}$ between the different exposure subgroups we used the Tukey modified $t$ test.

Logistic regression analysis was used to test the association between exposure and respiratory symptom-based categorical outcomes expressed as ORs and 95\% CIs. The models tested included the covariates of age (continuous), parental asthma/ atopy (yes/no), smoking status (ever smoker=yes, neversmoker=no) and regular exposure to second-hand smoke (SHS) at home and/or at work (yes/no). The effect of exposure on lung function was analysed using multiple linear regression. Separate models were tested for each of five outcomes: FVC, $\mathrm{FEV}_{1}, \mathrm{FVC} \%$ predicted, $\mathrm{FEV}_{1} \%$ predicted and $\mathrm{FEV}_{1} / \mathrm{FVC}$ ratio. Models of FVC, $\mathrm{FEV}_{1}$ and $\mathrm{FEV}_{1} / \mathrm{FVC}$ were adjusted for age, height, smoking status, SHS exposure, parental atopy/asthma and TAO for the work area of each subject. Models for FVC\% predicted and $\mathrm{FEV}_{1} \%$ predicted included the variables other than age and height (already accounted for in the lung function prediction equation). All analyses were performed in SPSS V.20.

\section{RESULTS}

The baseline characteristics of the study participants are presented in table 1 . Overall, the referent jewellery sales group was slightly older and had a higher mean body mass index than the exposed production workers, although these differences were not statistically significant $(\mathrm{p}>0.20)$. Cigarette smoking $(32 \%$ vs $26 \% ; p>0.20)$ and regular SHS exposure $(37 \%$ vs $30 \%$; $\mathrm{p}=0.44$ ) were slightly more prevalent among the exposed workers, although these were present in a minority of participants in both groups and the differences were not statistically significant.

Urinary Cd levels are shown in table 2. The urinary Cd level among the exposed group overall was 10 times higher than in the referent group (geometric mean $5.8 \pm 2.2 \mu \mathrm{g} / \mathrm{dl}$ vs 0.41 $\pm 0.15 \mu \mathrm{g} / \mathrm{dl} ; \mathrm{p}<0.001)$. Among the three exposure subcategories there was a twofold difference between the highest exposure group (fabricating) and the lowest exposure group (buffing/polishing) (geometric mean $8.3 \pm 0.7 \mu \mathrm{g} / \mathrm{dl}$ vs $3.87 \pm 0.72 \mu \mathrm{g} / \mathrm{dl}$ ). All three exposed groups differed significantly from each other in pairwise comparisons $(\mathrm{p}<0.01)$.

We obtained 22 area-level averaged measures of TAO for clusters of exposed workers in the three job task subcategories ranging from 138 to $510 \mathrm{ppm}$, as well as 14 averaged measures of the workstations of the referents (range 68-92 ppm). The concentrations of TAO by overall exposure and by subcategory are presented in table 3. The median TAO level for the exposed group was nearly threefold greater than for the referents. Within the exposure subcategories, buffing and polishing tasks were associated with the highest median TAO levels and fabricating with the lowest.

The frequencies of respiratory symptoms by exposure categories are presented in table 4. Overall, being in the exposed group was associated with substantially increased odds of reporting any respiratory symptom (OR 3.1; 95\% CI 1.4 to 7.3 ). The exposed workers reported a threefold higher prevalence of cough, wheezing and phlegm $(18.8 \%, 17.3 \%$ and $23.3 \%$, respectively) compared with the referent group $(5.5 \%, 5.5 \%$ and $7.4 \%$, respectively). Taking into account the covariates, the odds of each of the individual symptoms shown in table 4 were significantly elevated in the exposure group, except for eye irritation (in isolation from nasal symptoms).

Table 5 shows the spirometric findings for the referent and exposed groups. There were marked deficits in lung function associated with exposure. Overall, there was a $600 \mathrm{ml}$ mean

Table 4 Occurrence of respiratory symptoms in the study population

\begin{tabular}{|c|c|c|c|c|}
\hline Symptoms & Referents $(n=54)$ & Exposed $(n=133)$ & OR $(95 \% \mathrm{Cl})$ & $p$ Value \\
\hline Any respiratory tract symptom & $18(33.3)$ & $99(75.9)$ & 3.13 (1.37 to 7.28$)$ & 0.019 \\
\hline Prolonged cough & $3(5.5)$ & $25(18.8)$ & 4.93 (1.26 to 19.22$)$ & 0.021 \\
\hline Wheezing or whistling in chest & $3(5.5)$ & $23(17.3)$ & 3.65 (1.05 to 12.74$)$ & 0.042 \\
\hline Phlegm in chest & $4(7.4)$ & $31(23.3)$ & $3.92(1.26$ to 12.12$)$ & 0.017 \\
\hline Breathing trouble & $5(9.2)$ & $30(22.5)$ & $2.90(1.03$ to 8.16$)$ & 0.043 \\
\hline Nasal allergy & $10(11.1)$ & $56(27.8)$ & 3.49 (1.58 to 7.72$)$ & 0.002 \\
\hline Nasal problems with watery eyes & $2(3.7)$ & $27(20.3)$ & 4.55 (1.30 to 15.92$)$ & 0.017 \\
\hline \multicolumn{5}{|l|}{ Other symptoms } \\
\hline Eye problems & $5(9.2)$ & $15(11.3)$ & 1.21 (0.41 to 3.54$)$ & 0.726 \\
\hline Skin problems & $4(7.4)$ & $33(24.8)$ & 4.16 (1.38 to 12.58 ) & 0.011 \\
\hline
\end{tabular}

ORs (referent symptom prevalence $=1.0$ ) are adjusted for parental atopy or asthma, smoking and exposure to second-hand smoke at work and/or at home. Values for the respiratory symptoms do not add up to $100 \%$ due to multiple non-exclusive response categories. 
Table 5 Lung function by exposure among 133 jewellery production workers and 54 referents

\begin{tabular}{|c|c|c|c|c|c|}
\hline & \multicolumn{5}{|l|}{ Parameters } \\
\hline & FVC & FVC (\% predicted) & $\mathrm{FEV}_{1}$ & $\mathrm{FEV}_{1}$ (\% predicted) & $\mathrm{FEV}_{1} / \mathrm{FVC}$ \\
\hline \multicolumn{6}{|l|}{ Referent vs total exposed } \\
\hline Referent $(n=54)$ & $3.49 \pm 0.29$ & $92.7 \pm 4.6$ & $3.04 \pm 0.24$ & $92.2 \pm 2.8$ & $0.87 \pm 0.03$ \\
\hline Total exposed $(n=133)$ & $2.89 \pm 0.29$ & $83.9 \pm 5.9$ & $2.40 \pm 0.27$ & $81.8 \pm 5.9$ & $0.83 \pm 0.06$ \\
\hline \multicolumn{6}{|l|}{ Within exposure subcategories } \\
\hline Melting $(n=32)$ & $3.00 \pm 0.25$ & $86.1 \pm 6.6$ & $2.61 \pm 0.21$ & $85.6 \pm 5.5$ & $0.87 \pm 0.07$ \\
\hline Fabricating $(n=61)$ & $2.99 \pm 0.22$ & $84.9 \pm 4.2$ & $2.47 \pm 0.20$ & $82.4 \pm 4.5$ & $0.83 \pm 0.05$ \\
\hline Polishing/buffing $(n=40)$ & $2.64 \pm 0.27$ & $80.5 \pm 6.5$ & $2.12 \pm 0.18$ & $77.6 \pm 5.7$ & $0.81 \pm 0.06$ \\
\hline
\end{tabular}

exposure-associated difference in both FVC and $\mathrm{FEV}_{1}$ (all differences were significant at $p<0.01$ ). As a percentage of predicted values, the exposed group had lung function values $84 \%$ and $82 \%$ of predicted for FVC and $\mathrm{FEV}_{1}$, respectively. Overall, $51(38 \%)$ of the exposed workers had $\mathrm{FEV}_{1}$ values less than $80 \%$ age and height predicted. The mean $\mathrm{FEV}_{1} / \mathrm{FVC}$ ratio was also significantly lower among the exposed group than in the referents $(\mathrm{p}<0.01)$. Within the subcategories of exposure, all the lung function variables were significantly $(p<0.001)$ lower among the polishing workers compared with those engaged in melting or fabrication. Compared with workers engaged in melting, the fabricators had lower mean $\mathrm{FEV}_{1}$ and $\mathrm{FEV}_{1} / \mathrm{FVC}$ values whereas the mean FVC values were similar between these two groups.

The relationship between urinary $\mathrm{Cd}$ concentrations and $\mathrm{FEV}_{1}$ is shown in figure 1 . This scatterplot shows that, although there is considerable variability, there is minimal overlap for both parameters between referents and the exposed group.

As shown in table 6, higher urinary Cd concentrations were associated with poorer lung function for each of the spirometric measures studied. Among the group as a whole $(n=187)$, for each increase in Cd of $1 \mu \mathrm{g} / \mathrm{dl}$ we observed a $34 \mathrm{ml}$ decrement in FVC and a $39 \mathrm{ml}$ decrement in $\mathrm{FEV}_{1}$, with a decline in the $\mathrm{FEV}_{1} / \mathrm{FVC}$ ratio by $3 \%$ for the same unit increase in urinary

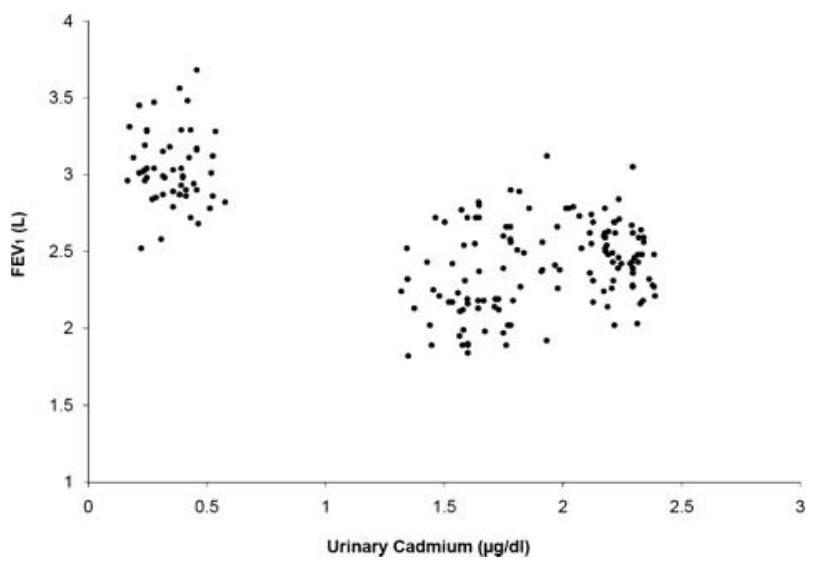

Figure 1 Forced expiratory volume in $1 \mathrm{~s}\left(\mathrm{FEV}_{1}\right)$ in relation to urinary cadmium (Cd) levels among referents (cluster to upper left) and exposed workers (cluster to lower right). The urinary $\mathrm{Cd}$ values have been transformed, taking the natural logarithm of 1 plus the observed value.
Cd. The analyses within the exposed group alone (ie, excluding the referents) demonstrated a similar exposure response, albeit more pronounced (FVC deficit of $40 \mathrm{ml}$ and $\mathrm{FEV}_{1}$ deficit of $65 \mathrm{ml}$ per $1 \mu \mathrm{g} / \mathrm{dl}$ urinary $\mathrm{Cd}$ ).

\section{DISCUSSION}

We observed large and clinically relevant decrements in lung function associated with a $\mathrm{Cd}$ exposure response. This relationship takes into account airborne oxidant co-exposures, which were highest among the polishing workers, the group with a lower Cd exposure. The lung function decrement and symptom prevalence in this cohort underscores the clinical impact of the multifactorial poor hygienic conditions experienced by these jewellery workers.

The urinary Cd levels were highest among the fabricating workers, which is consistent with Cd-containing solder as the principal exposure source. A recent Indian press report highlighted the use of Cd-containing solder in gold jewellery. ${ }^{20}$ Acute Cd inhalation toxicity from solder brazing has been documented in case reports from silver jewellery making in India. $^{21} 22$ Subacute to chronic Cd exposure from 'silver solder' has been well-recognised in jewellery fabrication and in other industrial brazing applications. ${ }^{23} 24 \mathrm{Cd}$ overexposure from gold and silver alloying with $\mathrm{Cd}$ has also been reported. ${ }^{25}$

$\mathrm{Cd}$ is toxic to various biological systems. ${ }^{26-31}$ Among these, the respiratory tract is a key target organ with emphysema being a particularly important endpoint. An investigation of 101 Cd-exposed workers showing lung function decrements including lung carbon monoxide transfer factor (TLCO), a marker of emphysema, is especially noteworthy. ${ }^{8}$ Other occupational studies of respiratory effects due to $\mathrm{Cd}$ have yielded mixed results. Three studies (total exposed $n=120$ ) have shown Cd-associated adverse lung function deficits 91012 while another observed an increased risk of respiratory mortality. ${ }^{11}$ In contrast, three other studies of Cd-exposed workers (total exposed $n=205$ ) did not observe lung function decrements. ${ }^{13-15}$ In the only study of jewellery workers using Cd-containing solder, only 8 of 25 workers with brazing fume exposure had detectable urine levels $(>0.4 \mu \mathrm{g} / \mathrm{dl})$; pulmonary function was described as 'normal' in all but one worker with asthma. ${ }^{23}$ The current study adds substantially to this pool of data and drives the balance of findings in support of Cd-associated adverse effects on lung function in humans.

Limitations of our study include its cross-sectional design and the possibility that acute and subacute effects were 
Table 6 Effect $(\beta)$ of occupational exposure on lung function

\begin{tabular}{|c|c|c|}
\hline \multirow[b]{2}{*}{ Parameters } & \multicolumn{2}{|l|}{$\boldsymbol{\beta}$ value $(95 \% \mathrm{Cl})$} \\
\hline & All subjects $(n=187)$ & Exposed workers only $(n=133)$ \\
\hline FVC (I) & $-0.034(-0.044$ to -0.023$)$ & $-0.04(-0.07$ to -0.009$)$ \\
\hline FVC $\%$ predicted & $-0.84(-1.08$ to -0.60$)$ & $-1.53(-2.31$ to -0.76$)$ \\
\hline $\mathrm{FEV}_{1}(\mathrm{I})$ & $-0.039(-0.033$ to -0.044$)$ & $-0.065(-0.08$ to -0.05$)$ \\
\hline $\mathrm{FEV}_{1} \%$ predicted & $-1.00(-1.21$ to -0.79$)$ & $-1.99(-2.69$ to -1.28$)$ \\
\hline $\mathrm{FEV}_{1} / \mathrm{FVC}$ & $-0.003(-0.006$ to -0.001$)$ & $-0.011(-0.02$ to -0.003$)$ \\
\hline
\end{tabular}

superimposed on a cumulative impairment. One controlled study of toxic $\mathrm{Cd}$ exposure showed an acute decrement in $\mathrm{FEV}_{1}, \mathrm{FVC}$ and TLCO $24 \mathrm{~h}$ after intentional exposure followed by at least partial recovery at $48 \mathrm{~h} .{ }^{32}$ We did not measure TLCO in our study, although this is likely to be an important endpoint in Cd toxicity. ${ }^{8}$ Although our urinary measurements were not adjusted for creatinine concentration, such measurement imprecision is likely to have been non-systematic, although a recent study of child labourers manufacturing surgical instruments in Pakistan found that exposure-related differences in urine chromium levels were actually even greater with creatinine adjustment. ${ }^{33}$ It is important, too, to emphasise that Cd was not the only relevant exposure in the jewellery workshops that we studied. We took airborne TAO into account but did not characterise this exposure further. One source may have been nitric acid (such exposure has been reported in the Indian jewellery industry ${ }^{34}$ ), and other oxidants may have been produced by charcoal-fuelled metal alloying or flame torch-based brazing. An independent negative effect of concomitant TAO exposure on lung function is consistent with the greatest decrement in lung function occurring in polishers who had the highest TAO values yet relatively lower Cd levels (albeit substantially higher than the referents). Although we took this effect into account in our analysis, our study was not designed or powered to assess potential multiplicative interactions among combined risk factors. Furthermore, we did not measure area-level or personal airborne $\mathrm{Cd}$ or other particulates. Based on standard industrial hygiene principles, the working conditions were consistent with airborne $\mathrm{Cd}$ fume inhalation being the salient route of exposure, but we cannot exclude concomitant $\mathrm{Cd}$ exposure via ingestion. There were potential selection effects in that those excluded from the study were less likely to be ever smokers. Nonetheless, the proportion of ever smokers in the study group was not high and we took active smoking and SHS exposure into account in our multivariate analysis. There could have been other unmeasured confounders that we did not assess. Socioeconomic status probably differed between the referents and exposed groups, but there should not have been a gradient within the exposed subcategories, all of whom were drawn from multiple small worksites not typically recruited into occupational studies.

The adverse exposure effects we found underscore the deplorable conditions experienced by the jewellery workers that we studied. Clearly, there is a serious need for systematic surveillance of respiratory status in this population and enforcement of adequate protective measures.

Acknowledgements The authors thank Professor Pulok Mukherjee, Department of Pharmaceutical Technology, Jadavpur University, Kolkata, India for providing the AAS facility and Mr Neelesh Nema for assisting in the assay.
Contributors SM designed the study, collected and analysed data. PDB analysed and interpreted the data and wrote the manuscript. SS designed and supervised the study and took the final decision to submit the manuscript.

Funding The study was partially financed by INSPIRE fellowship grants (Sanction Letter No-DST/INSPIRE FELLOWSHIP/2010/302) awarded by the Department of Science and Technology of the Government of India to SM and the DST PURSE Programme (Government of India) of University of Kalyani to SS.

\section{Competing interests None.}

Ethics approval Ethical approval was obtained from the Departmental Research Committee of the Department of Physiology, University of Kalyani and participants provided signed consent.

Provenance and peer review Not commissioned; internally peer reviewed.

\section{REFERENCES}

1 Nemery B. Metal toxicity and the respiratory tract. Eur Respir J 1990;3:202-19.

2 Anthony JS, Zamel N, Aberman A. Abnormalities in pulmonary function after brief exposure to toxic metal fumes. J Can Med Assoc 1978;119:586-8.

3 Fourtes L, Leo A, Ellerbeck PG, et al. Acute respiratory fatality associated with exposure to sheet metal and cadmium fumes. Clin Toxicol 1991:29:279-83.

4 Kirschvink N, Martin N, Fievez L, et al. Airway inflammation in cadmium-exposed rats is associated with pulmonary oxidative stress and emphysema. Free Radic Res 2006; 40:241-50.

5 Zhang $W$, Fievez $L$, Zhang $F$, et al. Effects of formoterol and ipratropium bromide on repeated cadmium inhalation-induced pulmonary inflammation and emphysema in rats. Eur J Pharmacol 2010;647:178-87.

6 Mannino DM, Holguin F, Greves HM, et al. Urinary cadmium levels predict lower lung function in current and former smokers: data from the Third National Health and Nutrition Examination Survey. Thorax 2004;59:194-8.

7 Lampe BJ, Park SK, Robins T, et al. Association between 24-hour urinary cadmium and pulmonary function among community-exposed men: the VA Normative Aging Study. Environ Health Perspect 2008;116:1226-30.

8 Davison AG, Newman Taylor AJ, Darbyshire J, et al. Cadmium fume inhalation and emphysema. Lancet 1988;331:663-7.

9 Lauwerys RR, Roels HA, Budet J-P, et al. Investigation of the lung and kidney function in workers exposed to cadmium. Environ Health Perspect 1979;28:137-45.

10 Sakurai $\mathrm{H}$, Omae K, Toyama $\mathrm{T}$, et al. Cross-sectional study of pulmonary function in cadmium alloy workers. Scand J Work Environ Health 1982;8:122-30.

11 Sorahan T, Lister A, Gilthorpe MS, et al. Mortality of copper cadmium alloy workers with special reference to lung cancer and non-malignant diseases of the respiratory system, 1946-92. Occup Environ Med 1995;52:804-12.

12 Jakubowski M, Abramowska-Guzik A, Szymczak W, et al. Influence of long-term occupational exposure to cadmium on lung function tests results. Int J Occup Med Environ Health 2004;17:361-8.

13 Chan OY, Poh SC, Lee HS, et al. Respiratory function in cadmium battery workers- a follow-up study. Ann Acad Med Singapore 1988;17:283-7.

14 Cortona G, Apostoli P, Toffoletto F, et al. Occupational exposure to cadmium and lung function. IARC Sci Pub 1992;118:205-10.

15 Edling $C$, Elinder CG, Randma E. Lung function in workers using cadmium containing solder. Br J Ind Med 1986:43:657-62.

16 Jarvis D, Chinn S, Luczynska $C$, et al. The association of smoking with sensitization to common environmental allergens: results from the European Community Respiratory Health Survey. J Allergy Clin Immunol 1999;104:934-40.

17 American Thoracic Society. Standardization of spirometry, 1994 update. Am J Respir Crit Care Med 1995;152:1107-36. 
18 Kamat SR, Tyagi NK, Rashid SSR. Lung function in Indian adult subjects. Lung India $1982 ; 1: 11-21$

19 Haagen-Smit AJ, Brunelle MF. The application of phenolphthalein reagent to atmospheric oxidant analysis. Int J Air Pollut 1958;1:51-9.

20 Thomas M. All that glitters is not gold, it could be cadmium. Times of India 18 May 2011. http://articles.timesofindia.indiatimes.com/2011-05-18/surat/ 29555535_1_hallmarked-jewellery-articles-cadmium (accessed 17 Oct 2012).

21 Panchal L, Vaideeswar P. Acute lung injury due to cadmium inhalation-a case report. Indian J Pathol Microbiol 2006;49:265-6.

22 Sethi PK, Khandelwal D, Sethi N. Cadmium exposure: health hazards of silver cottage industry in developing countries. J Med Toxicol 2006;2:14-15.

23 Baker EL, Peterson WA, Holtz JL, et al. Subacute cadmium intoxication in jewelry workers: an evaluation of diagnostic procedures. Arch Environ Health 1979;34:173-7.

24 Mason HJ, Williams N, Armitage S, et al. Follow up of workers previously exposed to silver solder containing cadmium. Occup Environ Med 1999:56:553-8.

25 Wittman R, Hu H. Cadmium exposure and nephropathy in a 28-year old female metals worker. Environ Health Perspect 2002;110:1261-6.

26 Stayner L, Smith R, Thun M, et al. A dose-response analysis and quantitative assessment of lung cancer risk and occupational cadmium exposure. Ann Epidemiol 1992;2:177-94.
27 Nawrot T, Plusquin M, Hogervorst J, et al. Environmental exposure to cadmium and risk of cancer: a prospective population-based study. Lancet Oncol 2006;7:119-26.

28 Godt J, Scheidig F, Grosse-Siestrup C, et al. The toxicity of cadmium and resulting hazards for human health. J Occup Med Toxicol 2006;1:22

29 Plaza MT, Navas-Acien A, Crainiceanu CM, et al. Cadmium exposure and hypertension in the 1999-2004 National Health and Nutrition Examination Survey (NHANES). Environ Health Perspect 2008;116:51-6.

30 Nawrot TS, Staessen JA, Roels HA, et al. Cadmium exposure in the population: from health risks to strategies of prevention. Biometals 2010;23:769-82.

31 Lee MS, Park SK, Hu H, et al. Cadmium exposure and cardiovascular disease in the 2005 Korea National Health and Nutrition Examination Survey. Environ Res 2011;111:171-6.

32 Johnson JS, Kilburn KH. Cadmium induced metal fume fever: results of inhalation challenge. Am J Ind Med 1983;4:533-40.

33 Sughis M, Nawrot TS, Haufroid V, et al. Adverse health effects of child labor: high exposure to chromium and oxidative DNA damage in children manufacturing surgical instruments. Environ Health Perspect 2012;120:1469-74.

34 Jayakumar R, Sasikala K. Evaluation of DNA damage in jewellery workers occupationally exposed to nitric oxide. Environ Toxicol Pharmacol 2008:26:259-61. 